\title{
Treatment outcomes of primary and recurrent inverted papilloma: an analysis of 96 cases
}

\author{
Joo-Heon Yoon, M.D. ${ }^{*} \dagger$, Chang-Hoon Kim, M.D. , Eun Chang Choi, M.D."
}

\begin{abstract}
This series was undertaken to investigate the incidence of associated polyps and the recurrence rates of inverted papillomas with, or without, malignancies, as well as the treatment outcomes of the recurred cases.

A retrospective study evaluating the pathology, associated polyps, types of operation, recurrence rate after original operation, and surgical outcomes of recurred cases was conducted upon 96 patients diagnosed with inverted papilloma.

The overall malignancy rate was 11.5 per cent with synchronous tumours accounting for 9.4 per cent and metachronous for 2.1 per cent. Inflammatory polyps were found in association with inverted papilloma in 21.9 per cent. In cases without malignancies, the recurrence rate after the original conservative procedure was 33.9 per cent, compared to 14.3 per cent after a medial maxillectomy. In cases with malignancies, the recurrence rate after the original surgical procedure was 22.2 per cent.

Our study indicates that more aggressive and bolder surgical resection of inverted papilloma should be undertaken as a primary treatment method, or as a treatment for recurrent cases to reduce the recurrence rate of inverted papilloma with, or without, malignancy.
\end{abstract}

\section{Key words: Nose; Papilloma, Inverted; Treatment Outcome}

\section{Introduction}

Inverted papilloma is a relatively uncommon sinonasal lesion constituting 0.5 per cent to four per cent of all nasal tumours. ${ }^{1}$ Its aetiology and pathogenesis are still uncertain. Suggested aetiologies are viral infections, smoking, allergy, chronic inflammations and occupational exposures. ${ }^{2,3}$ However, these aetiologies are not supported by any convincing evidence. 4

The four characteristic attributes of inverted papilloma are its tendency to recur, its destructive capacity, the associated nasal polyps, and its propensity to be associated with malignancy. Because of its high recurrence rate and aggressive nature, management of inverted papilloma has changed from conservative intranasal piecemeal excision to a more aggressive wide excision by lateral rhinotomy combined with a medial maxillectomy. ${ }^{48}$ However, some authors have reported recently that an endoscopic endonasal approach can be performed in selected cases in which tumour extension is limited. $^{9-11}$

Few reports have been published on the relationship between polyp and inverted papilloma, and on the treatment outcome of recurrent inverted papilloma. Thus, this work was undertaken to investigate the incidence of associated polyps and the recurrence rate of inverted papillomas with or without malignancies, in terms of the type of operation and the treatment outcomes of recurrent cases.

\section{Materials and methods}

Between 1988 and 1998, 96 patients were diagnosed with inverted papilloma and underwent operation at the Severance Hospital, Yonsei University College of Medicine, Seoul, Korea. A retrospective study evaluating pathology, associated polyps, types of operation, recurrence rate after original operation, and surgical outcomes of recurrent cases was conducted. Only histologically proven cases of inverted papilloma were included in this study. The follow-up period ranged from 24 to 72 months.

\section{Age and sex distribution}

Sixty-seven male patients and 29 female patients were diagnosed with inverted papilloma; the male to female ratio was approximately $2: 1$. Higher incidences were observed in the fifth, sixth and seventh decades, and there was no patient under the age of 30 (Table I).

From the Department of Otorhinolaryngology ${ }^{*}$ and BK21 Project for Medical Sciences ${ }^{\dagger}$ Yonsei University College of Medicine, 
TABLE I

SEX AND DISTRIBUTION OF PATIENTS

\begin{tabular}{cccc}
\hline Age & Male (\%) & Female $(\%)$ & $\begin{array}{c}\text { Number of } \\
\text { cases }(\%)\end{array}$ \\
\hline $31-40$ & 10 & 5 & $15(15.6)$ \\
$41-50$ & 18 & 7 & $25(26.0)$ \\
$51-60$ & 16 & 8 & $24(25.0)$ \\
$61-70$ & 21 & 6 & $27(28.1)$ \\
$71-$ & 2 & 3 & 5 \\
Total & $67(69.8)$ & $29(30.2)$ & $96(100)$ \\
\hline
\end{tabular}

\section{Results}

\section{Incidence of associated polyps}

Inverted papillomas were often incidentally found in endonasal ethmoidectomy and polypectomy, because inflammatory polyps surround the tumour. Inflammatory polyps were found in association with inverted papilloma in 21 (21.9 per cent) of the 96 cases in our study (Table II).

\section{Recurrence rate of inverted papillomas without malignancies}

Among the total 87 cases of inverted papillomas without malignancies, 59 cases were initially treated by endoscopic intranasal and/or transantral excision and 28 cases by medial maxillectomy via lateral rhinotomy or the midfacial degloving approach. The recurrence rate after endoscopic intranasal and/or transantral excision was 33.9 per cent (20 cases), and the recurrence rate after medial maxillectomy was 14.3 per cent (four cases) (Table III).

\section{Recurrence rate of inverted papillomas with malignancies}

In the pathological review, malignancies (Figure 1) were detected in nine cases of the 96 original cases; seven cases were diagnosed with squamous cell carcinoma and two with transitional cell carcinoma. The incidence of synchronous malignancy in our series was thus 9.4 per cent (Table I). Two cases of metachronous malignancy also occurred in the 96 cases (2.1 per cent). Thus the overall malignancy rate was 11.5 per cent; 9.4 per cent as synchronous malignancy and 2.1 per cent as metachronous malignancy. The nine cases of inverted papillomas with synchronous malignancy were treated with various options. One patient underwent medial maxillectomy via lateral rhinotomy and died of recurrent disease. Two patients underwent total maxillectomy with orbital exenteration and both

TABLE II

PATHOLOGY RESULTS

\begin{tabular}{|c|c|c|}
\hline Pathology & Number of cas & es $(\%)$ \\
\hline IP without malignancy & $87(90.6)$ & \\
\hline IP alone & 63 & $(65.6)$ \\
\hline IP with polyp & 21 & (21.9) \\
\hline IP with atypia or dysplasia & 3 & (3.1) \\
\hline IP with malignancy (synchronous) & $9 \quad(9.4)$ & \\
\hline IP with squamous cell carcinoma & ) & (7.3) \\
\hline IP with transitional cell carcinoma & 2 & (2.1) \\
\hline Total & $96(100)$ & \\
\hline
\end{tabular}

IP: inverted papilloma
TABLE III

RECURRENCE RATES AFTER ORIGINAL TREATMENTS

\begin{tabular}{lrrr}
\hline Operation & \multicolumn{2}{c}{ Recurred/total (\%) } \\
\hline IP without malignancy & $24 / 87(27.6)$ \\
Endoscopic intranasal and/or & \multicolumn{2}{c}{$20 / 59(33.9)$} \\
transantral excision & \multicolumn{2}{c}{$4 / 18(14.3)$} \\
MM via LR or MDA & $2 / 9$ & $(22.2)$ & \\
IP with malignancy & $1 / 1(100.0)$ \\
MM + RT & & $0 / 2$ & $(0.0)$ \\
TM with orbital exentration + RT & & $1 / 6$ & $(16.7)$ \\
Craniofacial resection + RT & & \\
Total & $26 / 96(27.1)$ \\
\hline
\end{tabular}

IP = inverted papilloma; $\mathrm{MM}=$ medial maxillectomy; $\mathrm{LR}=$ lateral rhinotomy; MDA = midfacial degloving approach; $\mathrm{TM}=$ total maxillectomy; $\mathrm{RT}=$ radiation therapy .

showed no evidence of disease. Six patients were treated with craniofacial resection for extensive disease, and five of these six showed no evidence of disease, and one patient died of recurrent cancer. All patients with malignancies received post-operative radiation therapy. In our series, 22.2 per cent (two of nine cases) of inverted papilloma with malignancy cases showed recurrence within the minimum follow-up of 36 months (Table III).

\section{Surgical outcomes of recurrent inverted papillomas}

A total of 26 cases (27.1 per cent) recurred out of 96 cases. Unfortunately, nine out of 26 cases were lost during follow-up for over 24 months because the subjects moved frequently. Among the 17 cases that were analysed, 13 cases recurred after an endoscopic intranasal and/or transantral excision, and four cases after a medial maxillectomy. As a secondary treatment method for the 13 recurrent cases after an endoscopic intranasal and/or transantral excision, medial maxillectomy was performed in eight cases, and repeated endoscopic intranasal and/or transantral excision in four cases. One patient developed metachronous malignancy and refused surgical treatment. This patient was treated with radiation therapy for palliation but died of disease. All of the patients treated with a medial maxillectomy as a secondary treatment method showed no evidence of

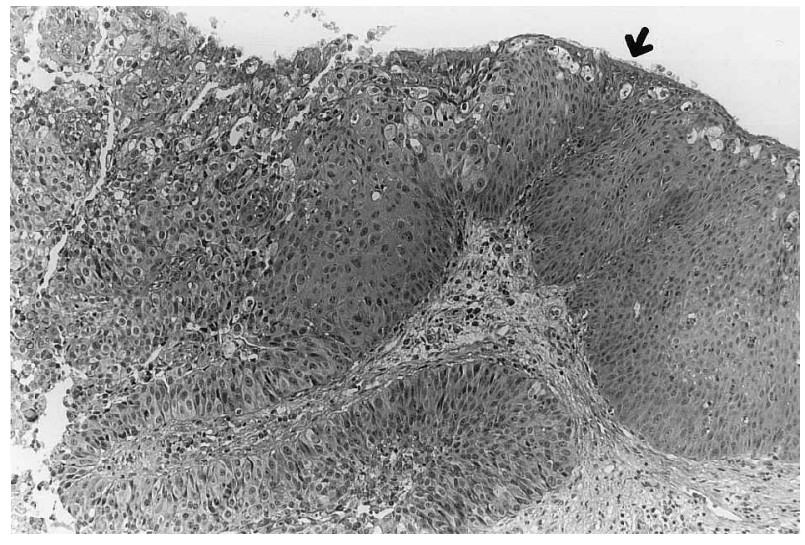

FIG. 1

Light microscopic finding of a case inverted papilloma with malignancy. The arrows point to the lesions that show a transition from the benign papilloma to the invasive squamous cell carcinoma. $(\mathrm{H} \& \mathrm{E} ; \times 200)$. 
TABLE IV

SECONDARY TREATMENT METHODS IN RECURRED CASES

\begin{tabular}{lclcc}
\hline $\begin{array}{c}\text { Primary treatment } \\
\text { method }\end{array}$ & $\begin{array}{c}\text { Time to recurrence } \\
\text { (months) }\end{array}$ & \multicolumn{1}{c}{ Secondary treatment method } & $\begin{array}{c}\text { Follow-up period } \\
\text { (months) }\end{array}$ \\
\hline $\begin{array}{c}\text { Endoscopic intranasal } \\
\text { and/or transantral } \\
\text { excision (13) }\end{array}$ & $3-36$ & $\begin{array}{l}\text { Medial maxillectomy (8) } \\
\text { Endoscopic intranasal and/or transantral excision (4) }\end{array}$ & $\begin{array}{c}\text { NED (8) } \\
\text { NED (2) } \\
\text { R (2) }\end{array}$ & $\begin{array}{c}24-72 \\
24-72\end{array}$ \\
& & $\begin{array}{l}\text { Radiation therapy (1) } \\
\text {-Development of metachronous cancer }\end{array}$ & DOD (1) \\
$\begin{array}{c}\text { Medial maxillectomy } \\
\text { via LR or MDA (4) }\end{array}$ & $10-16$ & Endoscopic intranasal and/or transantral excision (3) & NED (2) & $24-28$ \\
& & R (1) & NED (1) \\
\hline
\end{tabular}

$\overline{\mathrm{LR}}=$ lateral rhinotomy; MDA = midfacial degloving approach; NED = no evidence of disease; DOD = died of disease; $\mathrm{R}=$ recurrence.

disease. Of the four patients who underwent repeated endoscopic intranasal and/or transantral excision, there were two cases of recurrence. Of the four recurrences after a medial maxillectomy, three patients underwent an endoscopic intranasal and/or transantral excision as the secondary treatment method. One case of recurrence in these three patients was observed. The remaining patient developed cancer and underwent a craniofacial resection and is without evidence of recurrence thus far (Table IV).

\section{Discussion}

Inverted papilloma is known to have a peak incidence in patients during their fifth to seventh decades, ${ }^{1-3,12}$ and our results support these reports. There were no patients under the age of 30 and especially no patients of paediatric age. Paediatric patients are commonly considered to be more susceptible to viral infections, known to be one of the aetiologic factors of inverted papilloma. ${ }^{2,3}$ Our results showed a 70 per cent male predominance (67 male, 29 female), and the male to female ratio was approximately $2: 1$, that is in agreement with most recorded series. ${ }^{1-3}$

Inverted papillomas are often found incidentally during ethmoidectomy and polypectomy, because inflammatory polyps may surround the tumour and the tumour cannot easily be observed during endoscopic examinations without removing these polyps. In our series, inflammatory polyps were found in association with inverted papilloma in 21 cases (21.9 per cent) out of the total 96 cases (Table II). This is similar to the result of another respect of 23 per cent, ${ }^{4}$ which suggests that chronic inflammation could be an important aetiologic factor of inverted papilloma. This also suggests that irregularly surfaced polyps or mucosae during ethmoidectomy and polypectomy should be confirmed by tissue biopsy.

The recurrence rate of inverted papilloma without malignancy depends on the extent and type of operation. The recurrence rate, after medial maxillectomy, ranged from 0 per cent to 30 per cent, ${ }^{8}$ and after conservative resection, ranged from 10 per cent $^{12}$ to 74 per cent ${ }^{8}$ in other reports. In our series, the recurrence rate of inverted papilloma without malignancy was 33.9 per cent with conservative resection, and 14.3 per cent with medial maxillectomy. As other authors have repeatedly shown, $1,5,7,12,13$ our series indicates that aggressive surgical procedure can reduce the recurrence rate of inverted papilloma. Our conservative-treatment group showed a somewhat higher recurrence rate (33.9 per cent) when compared with other reported conservative-treatment groups (around 18 per cent) ${ }^{8,9}$ This can be explained by two reasons. The first reason is that endoscopic surgery was overused in cases with extensive inverted papillomas when endoscopic surgery was first introduced in the late 1980s. That is to say, poor patient selection was one of the reasons. The second reason is that surgical skills were not advanced enough to handle the disease during the initial two years after the endoscopic surgery technique was introduced.

Recurrence is either the result of incomplete removal of the original tumour ${ }^{12}$ or is a consequence of retained areas of predisposed mucosa. ${ }^{2}$ According to previous studies, the recurrence rate of inverted papilloma has been reported to be as high as 30 per cent $^{8}$ even after the medial maxillectomy. Such a high recurrence rate cannot be explained by incomplete tumour resection alone. Human papilloma virus DNA is present in both the papilloma lesion and the cells of neighbouring normal-appearing mucosa. $^{2}$ Therefore, we believe that removing a certain amount of the neighbouring normal-appearing predisposed mucosa is required to reduce the rate of tumour recurrence. It is mandatory to elucidate more precisely the aetiology of inverted papilloma and develop ways of distinguishing between predisposed mucosa and normal mucosa at the time of surgery.

Some speculate that the success rate of a lateral rhinotomy is related to the en bloc resection of the lateral nasal wall. ${ }^{2,12}$ However, in our experience, there were only a few cases where complete en bloc resection was possible. Because the inverted papilloma is usually soft and friable, even with a medial maxillectomy it is impossible to perform a complete en bloc resection without piecemeal removal, especially in those cases with a posterior extension of the tumour beyond the posterior wall of the maxillary sinus. This could be the reason behind the somewhat higher rate of recurrence of inverted papilloma even after medial maxillectomy. 
Few reports have focused on the recurrence rate of inverted papillomas with malignancies. Our series had nine cases (9.4 per cent) of inverted papillomas with synchronous malignancy, that were treated with various options. One patient, treated with a medial maxillectomy and radiation therapy for inverted papilloma with malignancy, died of the recurrent cancer. Interestingly, however, there was only one recurrence of carcinoma in all eight patients who underwent a total maxillectomy or craniofacial resection. This surgical outcome is far better than that of other types of paranasal sinus cancers, and could be because the malignant cells are located in relatively few portions of the tumour mass, and that the portion of the mass invading beyond the sinus cavity may not have the true malignant cells. Accordingly, en bloc resection of inverted papilloma with malignancy, in accord with oncological principles, can actually provide an even wider safety margin than that of surgery in true malignant sinus cancers. Therefore, more aggressive surgical resection of inverted papillomas, even of those with malignancies, as a primary treatment method is a key to success and we would also stress that the best opportunity to remove the tumour completely is during the original operation. ${ }^{2}$ Because the malignant portion could not be differentiated from the non-malignant surrounding inverted papilloma by any means, even by magnetic resonance imaging (MRI), the malignancy could not be staged preoperatively.

With respect to the surgical outcomes of recurrent inverted papilloma, 13 cases of recurrences occurred after conservative primary excision. Among these 13 cases, medial maxillectomy was performed in eight and these showed no evidence of recurrence. Four cases out of the 13 were treated by repeated conservative excision and two cases showed repeated recurrence. Moreover, among the two cases of recurred inverted papillomas with metachronous malignancies, one patient died of recurrent cancer after radiation therapy for palliation. On the other hand, the other patient underwent a craniofacial resection and showed no evidence of disease for 72 months. These results indicate that more aggressive and bolder surgical excision of tumours is necessary, even in the case of recurrences with, or without, malignancies.

In summary, we conclude that the results of the surgical treatment of inverted papillomas, with, or without, malignancies, depend on the completeness of tumour excision in the primary treatment, and in the treatment of recurred cases.

\section{Conclusion}

Our study indicates that irregularly surfaced polyps or mucosae encountered during ethmoidectomy and polypectomy should be confirmed by tissue biopsy. We also speculate that more aggressive and bolder surgical resection of inverted papilloma is required as a primary treatment method and as a treatment for recurrent cases to reduce the recurrence rate of inverted papilloma with, or without, malignancy.

\section{Acknowledgement}

The authors would like to thank Dr W. I. Yang, department of pathology for his valuable contribution.

\section{References}

1 Lawson W, Ho BT, Shaari CM, Biller HF. Inverted papilloma: a report of 112 cases. Laryngoscope 1995;105: 282-8

2 Vrabec DP. The inverted schneiderian papilloma: a $25-$ year study. Laryngoscope 1994;104:582-605

3 Kerschner JE, Futran ND, Caney V. Inverting papilloma associated with squamous cell carcinoma and adenocarcinoma: case report and review of the literature. Am $J$ Otolaryngol 1996;17:257-9

4 Raveh E, Feinmesser R, Shpitzer T, Yaniv E, Segal K. Inverted papilloma of the nose and paranasal sinuses: a study of 56 cases and review of the literature. Isr J Med Sci 1996;32:1163-7

5 Phillips PP, Gustafson RO, Facer GW. The clinical behavior of inverting papilloma of the nose and paranasal sinuses: report of 112 cases and review of the literature. Laryngoscope 1990;100:463-9

6 Outzen KE, Grontveld A, Jorgensen K, Clausen PP, Ladefoged C. Inverted papilloma: incidence and late results of surgical treatment. Rhinology, 1996;34:114-8

7 Segal K, Atar E, Mor C, Har-El G, Sidi J. Inverting papilloma of the nose and paranasal sinuses. Laryngoscope 1986;96:394-8

8 Bielamowicz S, Calcaterra C, Watson D. Inverting papilloma of the head and neck: the UCLA update. Otolaryngol Head Neck Surg 1993;109:71-6

9 Benninger MS, Lavertu P, Levine H, Tucker HM. Conservation surgery for inverted papillomas. Head Neck 1991;13:442-5

10 Stankiewicz JA, Girgis SJ. Endoscopic surgical treatment of nasal and paranasal sinus inverted papilloma. Otolaryngol Head Neck Surg 1993;109:988-95

11 Waitz G, Wigand ME. Results of endoscopic sinus surgery for the treatment of inverted papillomas. Laryngoscope 1992;102:917-22

12 Lawson W, Benger JL, Som P, Bernard PJ, Biller HF. Inverted papilloma: an analysis of 87 cases. Laryngoscope 1989;99:1117-24

13 Myers EN, Fernau JL, Johnson JT, Tabet JC, Barnes EL. Management of inverted papilloma. Laryngoscope 1990; 100:481-90

Address for correspondence:

Joo-Heon Yoon, M.D., Ph.D.,

134 Shinchon-dong, Seodaemun-gu,

Department of Otorhinolaryngology,

Yonsei University College of Medicine,

Seoul, 120-752,

Korea.

Fax: 82-2-393-0580

E-mail: jhyoon@yumc.yonsei.ac.kr

Dr J.-H. Yoon takes responsibility for the integrity of the content of the paper.

Competing interests: None declared 